\title{
Recent Auction of Tanintharyi Coinage Sheds Historical Light on Myanmar Region
}

\author{
Philip Hauret \\ Independent Scholar, Honolulu, Hawaii, USA
}

Email address:

phauret@hawaii.rr.com

\section{To cite this article:}

Philip Hauret. Recent Auction of Tanintharyi Coinage Sheds Historical Light on Myanmar Region. History Research. Vol. 9, No. 1, 2021, pp. 1-11. doi: 10.11648/j.history.20210901.11

Received: December 18, 2020; Accepted: January 4, 2021; Published: January 12, 2021

\begin{abstract}
Since January 2019, Stephen Album Rare Coins of Santa Rosa, California (USA), a numismatic dealer specializing in Islamic and Asian coinage, has auctioned a major collection of the large tin-lead coins and weights of the Tanintharyi region of Myanmar (formerly known as Tenasserim). This unprecedented assemblage of 125 specimens has offered students of Myanmar numismatics a unique opportunity to study these coins, as today's on-line auctions provide quality digital photography unavailable in the past. This article introduces the reader to these coins by first reviewing the existing literature, beginning with European accounts from the seventeenth century and ending with the latest archaeological research papers addressing these coins. It will then examine seven select specimens from the Stephen Album auctions, several of which are previously unreported, that provide insights into Tanintharyi culture and communities from the seventeenth to early nineteenth centuries. This analysis will identify the only Tanintharyi coin discovered so far with a certain date and will examine a possibly mischaracterized date in another. It will also propose a translation of a previously misrepresented Tanintharyi coin and close with conclusions regarding the time period during which these coins were made, their economic function and the cultural contexts they may illuminate. The article reaches three major conclusions: 1) the manufacture and use of these coins began in the early seventeenth century and continued into the nineteenth century; 2) they functioned in local Tanintharyi economies and marketplaces and not in higher value trade between entrepots; and 3) they were issued by both official and private parties, with both entities utilizing cultural icons and traditions, rather than official titles or references, to generate acceptance of this medium of exchange.
\end{abstract}

Keywords: Burma, Myanmar, Tanintharyi, Tenasserim, Numismatics, Coins, Myeik, Dawei

\section{Introduction}

In the study of any society, the appearance of significant data sometimes goes unnoticed for the simple reason that the forum in which the data is disclosed is not frequented by the academic community. In the instance of the tin and lead coins of the Tanintharyi region of Myanmar (formerly known as Tenasserim), this appears to be the case. Since January 2019, 125 of these coins have appeared in the on-line auctions of Stephen Album Rare Coins (SARC), located in Santa Rosa, California (USA), a numismatic dealer that specializes in Islamic and Asian coinage. This unprecedented number of coins dwarfs earlier SARC auctions where usually none to a mere handful of Tanintharyi coins would appear for sale, consistent with the sales activity at other United States-based numismatic auctioneers. For instance, Stack's Bowers
Galleries of Santa Ana, California, a major numismatic firm with offices in Hong Kong and Paris, has listed just four of these coins since 2010 and only one actually sold [1], while Heritage Auctions, headquartered in Dallas, Texas, and the United States' largest auction house with offices in Hong Kong and London, has sold just one specimen since 2004 [2].

This virtual tsunami of Tanintharyi coins has offered students of Myanmar numismatics an unprecedented opportunity to study these coins, as today's on-line auctions provide high quality digital photography unavailable in the past. Equally unprecedented has been the prices these coins have commanded in the marketplace. Coins that would normally sell for anywhere between US\$100 and \$350 each, depending on condition and perceived rarity, have seen prices in many multiples of this range of value. Admittedly, not all of these coins have realized such prices, but few collectors 
would have predicted this kind of market several years ago.

When queried, SARC advised that this surge of Tanintharyi coinage was the sale of a large collection whose owner wishes to remain anonymous and was in the main completed in SARC's Auction 37 of July 2020. Other choice Tanintharyi items may continue to appear, however, if other owners decide to sell into what is perceived as a strong market [3]. We can say with certainty the emergence of these coins has attracted genuine attention to what has been until now a rather obscure field of collecting.

This article will introduce the reader to these coins by first reviewing the existing numismatic literature concerning them. We will then examine seven select specimens that have recently sold in SARC auctions, focusing on unreported coins or coins that may provide insights into Tanintharyi culture and communities during the subject time period.

\section{The Existing Literature}

The existing numismatic literature generally dates this variety of coinage from the mid-seventeenth century to the early nineteenth century, or roughly from the time the Taungoo (formerly Toungoo) Dynasty lost Tanintharyi to Ayuthia in the 1590's to the annexation of Tanintharyi by the British in 1825 . We do know this coinage continued to be used in the region following the First Anglo-Burmese War of 1824-1826, as English observers and colonial officials reported its use after the annexation, eventually to be supplanted by Anglo-Indian money [4-6].

The first mention of these coins in European literature came in 1679 from a French gem merchant and traveler named JeanBaptiste Tavernier, who on his fourth voyage to Asia visited Myanmar and described an octagonal tin coin depicting a serpent or sea dragon, which he erroneously attributed to the Malay sultanate of Kedah and Perak [5]. Avoiding the geographic error of Tavernier, another early mention came from Father Sangermano, an Italian missionary who resided in lower Myanmar from 1783 to 1808 . He noted the utilization of tin coins in the Tanintharyi region, but the ones he observed featured a cock, not a sea dragon [7].

Richard Carnac Temple, a British military officer who after the Third Anglo-Burmese War of 1885 presided over the colonial reshaping of Mandalay [8] and eventually became the President of the Yangon Port Commission [9], devotes considerable space to Tavernier's coin in his Indian Antiquary essay, "The Obsolete Tin Currency and Money of the Federated Malay States" [5]. Tavernier describes his tin coin as weighing 1.5 ounces, "thick in the sides, the middle being as thin as paper," and issued by the king of Kedah and Perak. Temple presents two graphics of the coin, one from Tavernier's original account, subjected to considerable creative reconstruction, and one from a sketch by the French numismatist H. C. Millies, who examined the subject coin in the Numismatic Museum of the Imperial Library in Paris approximately 200 years later. Representations of the latter sketch and what the coin would have looked like in a more pristine state are shown as Figures 1 and 2 respectively.

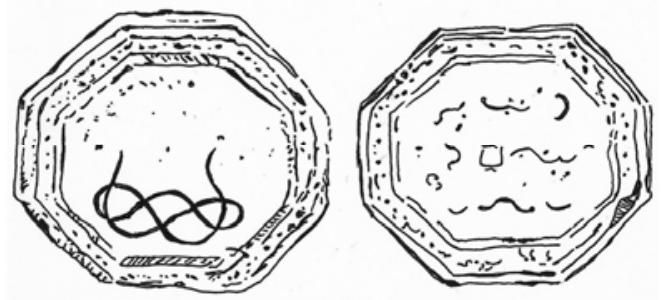

Figure 1. Millies' more accurate representation of the Tavernier coin.

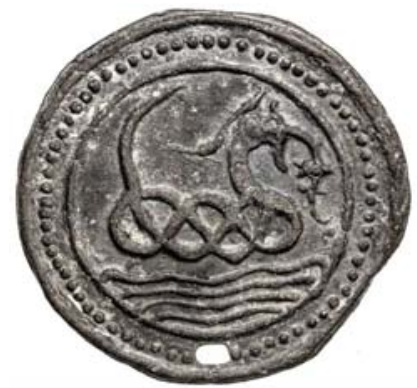

Figure 2. The obverse of Millies' coin in a more pristine state, a typical sea dragon design.

Millies noted the center square on the reverse side does not represent an actual hole, as previously believed, but might symbolize the relic chamber of a pagoda as contended by Arthur Phayre, a British colonial official who in 1882 published an essay on Myanmar coinage and had assisted Millies in his research. After noting that Tavernier never visited any Malay port, a point of some importance, Millies doubts the coin came from Kedah or Perak as it did not resemble any of the Malay coins he had seen. To the contrary, he concludes the coin was from Burma and featured an inscription in Burmese, not Persian or Arabic as would be expected if it was from Malaya during Tavernier's travels [5].

In terms of understanding Tanintharyi coinage, Temple's treatment of Tavernier's coin is the most valuable portion of his essay, but despite presenting without refutation Millies' clarifications on Burmese origin, he fails to grasp their implications by completely misrepresenting a Tanintharyi coin in Phayre's essay as having an "inscription obviously of Arabic origin" $[5,10]$. The coin displays Burmese writing, not Arabic (see Figure 3 for a representative coin). This is even more puzzling when just a page earlier Temple translates this Burmese inscription, "Mahasukha-nagara"1 (a transliteration taken from Phayre), as "City of great peace," while ignoring Phayre's translation "Land of great rest or happiness," despite citing his essay in the same footnote [5, 10]. Since later Malay coins refer to Kedah as Dāru' l-amān, the "Land of peace," Temple concludes that all coins with this inscription have a Kedah origin in spite of the contrary opinions of Millies and Phayre. To add to the confusion, several pages later he describes coins 9 and 11 of his own Plate III, exact reproductions of Phayre's specimens, as coins of Tanintharyi and not Kedah, despite one of them having the Mahasukha-nagara inscription [5, 10]. This is just the

1 Except for quoted material and well-known words and place names, this article will employ the transliteration system of the Myanmar-English Dictionary [12]. 
beginning of a series of scholarship errors by Temple, but fortunately subsequent research will provide wiser guidance and a more certain translation of Mahasukha-nagara.

An explanation for Temple's erroneous identification of this inscription as Arabic may be found in the 1844-1845 edition of the Numismatic Chronical and Journal of the Numismatic Society, published in London, which took up for detailed discussion a Tanintharyi coin depicting a "horse or buck" on one side and a Burmese inscription on the other. An accurate representation in pen and ink of ganagaran maha thu. khan, a different version of mahasukha-nagara, was provided, but it was not translated. We are tantalized by the observation that on one of the coins the letters "appear to be inverted and read the contrary way," following which is a slightly different inscription shown backwards as a demonstration (see Figure 3 for a representative coin).

Temple apparently never saw this article, for if he had it might have prevented his misidentification of these backward Burmese inscriptions as Arabic. Benjamin Nightingale, who submitted the Burmese writing, noted that these coins were used into the nineteenth century along the coast of Tanintharyi as far as Yangon, and in larger transactions would not be counted out individually but would be weighed in baskets [4].

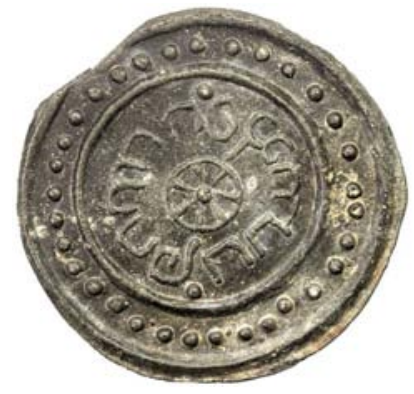

Figure 3. The backwards Burmese inscription that Temple alleged was Arabic.

We find the first comprehensive treatment of these coins in Phayre's previously mentioned essay, "The Coins of Arakan, of Pegu and of Burma" [10]. Phayre had served in the Tanintharyi and Rakhine (formerly Arakan) regions since 1835 and eventually became Commissioner of Rakhine in 1849. After the Second Anglo-Burmese War in 1852, he was appointed the Commissioner of Bago (formerly Pegu) province [11]. Per Phayre, these coins were of tin or a tinlead mixture and were in use in the Myeik (formerly Mergui) and Dawei (formerly Tavoy) regions of Myanmar, where significant deposits of tin are found. He believed they also had a religious purpose, as they were frequently deposited "in the relic chambers of pagodas" [10]. One specimen, weighing 11.75 ounces and depicting a hin: tha, or Brahminy duck, probably served as a marketplace weight, since such weights were frequently cast in the shape of that bird. Phayre's pictured coins also depicted a cock and a sea dragon, but the majority contained an image of a tou:, a mythological creature he described as a cross between a horse and deer (see Figure 4 for a representative coin).

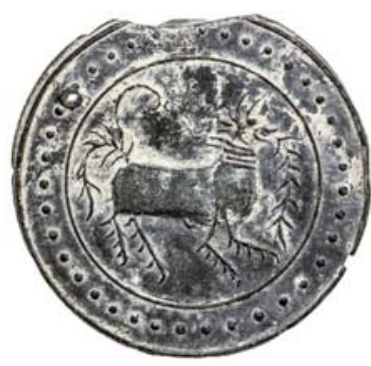

Figure 4. The obverse of a coin depicting a tou.

These coins possess the same inscription discussed earlier in the Numismatic Chronicle, maha thu. khan nagaran (seen on many of his coins as maha thu. khan ganagaran), which Phayre translated as "Land of great rest or happiness" and interpreted as the attainment of nirvana. In modern Burmese, thu. khan or "happiness" is spelled thu. kha. (see Figure 3) [12]. The religious nature of this expression is further demonstrated by the fact that all three words have a Pali origin. The use of nagaran, as opposed to the vernacular Burmese mjou. for "city" is noteworthy; the Burmese equivalent appears to be nagou, whose Pali origin is nagara [12]. This inscription encircles a spoked wheel on the coins' reverse, which Phayre believed symbolized the soul's trek to nirvana, and of the five shown in his photographic plates, three have the inscription written backwards as first noted in the Numismatic Chronicle [10].

Curiously, Phayre makes no mention of this backwards feature despite his propensity to attribute symbolical meanings to various features of Myanmar coins, and his lack of attention to this aspect probably guided Temple's trek into the swamp of Arabic inscriptions and Kedah origins.

\subsection{From Backwards to Retrograde}

We find a brief twentieth century treatment in Michael Mitchiner's Oriental Coins and Their Values: Non-Islamic States \& Western Colonies AD 600-1979, which examines four Tanintharyi coins [13], three of which depict the tou:, which he describes as a cross between a lion and deer. Coin no. 2862a features the maha thu. khan nagaran inscription (see Figure 3 for a similar coin), yet easily missed in Mitchiner's treatment of this coin is the word "retrograde," which he adds parenthetically without explanation and serves as a label for these backwards, mirror-image wise inscriptions first mentioned in [4]. In numismatics, the term has been used to describe the features of ancient Mediterranean coins made by counterfeiters who cut their dies as a direct copy of the target coin without realizing, or caring, that the product would demonstrate images and inscriptions in reverse [14]. Coin no. 2862 depicts a sea dragon on the obverse, while the reverse contains nine Burmese letters and syllables in a three by three arrangement that I initially believed was a cabalistic square called an in: (see Figure 5).

Upon further examination, I have concluded that Mitchiner has incorrectly rotated the coin 90 degrees to the left, and only when rotated 90 degrees to the right does the Burmese become readable. Once rotated, the Burmese appears to be ganara. ka la. thou' kha., which when corrected for missing 
letters, older or dialectal spellings and retrograde style becomes ganagara. ka la. thu. kha., or "City and age of happiness" [12], the only type encountered to date that contains a significant variation of "City of great happiness."

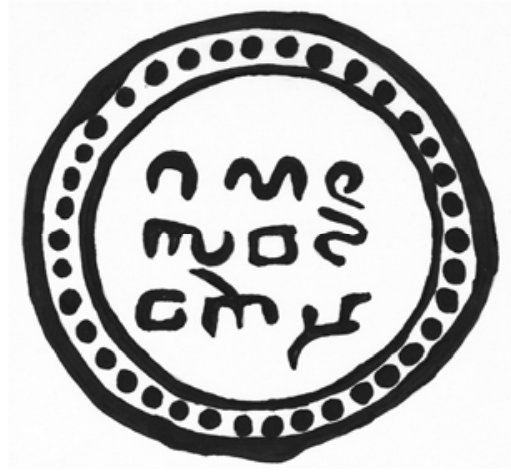

Figure 5. The cabbalistic inscription on the Mitchiner coin after rotating it 90 degrees.

In the case of Tanintharyi coins, retrograde could mean two things: one, the lettering is inscribed mirror-image wise; and two, the inscription is read counter-clockwise as it circles the center of the coin, or in the case of a coin where the inscription is linear and not circling a center device, the script would be read from right to left and either from the bottom line to the top or the top line to the bottom. Variations from these patterns will be encountered, however. In this article, "retrograde" will be the preferred label for describing such inscriptions.

\subsection{Robinson and Shaw}

Shortly after the release of Mitchiner's work, Michael Robinson and L. A Shaw, two British engineers and numismatists, published in 1980 what has been described by many as the "bible" of Myanmar numismatics, The Coins and Banknotes of Burma. Ambitious in its reach, it addresses every major monetary issuance since the first millennium, yet its section on Tanintharyi coinage is one of the shortest in the book, reflecting the apparent lack of data and specimens available to them [15]. After reproducing the two photographic plates from Phayre's essay and summarizing Phayre's and Temple's treatments, they also find fault with the latter's conclusions regarding the Kedah origin of these coins. They do note they were cast in molds, not struck by dies, and came with a typical diameter of $60 \mathrm{~mm}$ (over two inches) and a weight of approximately $30 \mathrm{~g}$, slightly over one ounce, details that Phayre did not provide. They feature photographs of three additional coins, all from British museums, two of which will be addressed here. The first type, pictured in Phayre and from the Manchester Museum, depicts the tou: on the obverse and a retrograde maha thu. khan nagaran (see Figures 3 and 4 for representative coins). Robinson and Shaw present the Burmese in pen and ink and translate it as "City of great rest or happiness," a refinement of Phayre's translation either by John Okell of the School of Oriental and African Studies or a number of Myanmar scholars who consulted on the book [15]. Since [12] defines thu. kha. as "happiness," "City of great happiness" will serve as the preferred translation in this article. Robinson and Shaw address the retrograde feature in this way: "On some specimens, including this one here, this appears in mirror image, i.e. the dies were cut positive rather than negative. For the same reason the animal is known facing either left or right" [15]. They offer no explanation for this, but as in the case of the ancient counterfeiters infer it was the product of careless or lazy die casting, as it would be easier for the die caster to create a mold with positive writing from his perspective, but resulting in a retrograde coin.

The second coin, from the Ashmolean Museum, appears to be quite rare as the author has been unable to identify another specimen of this type in the SARC sales or on the Museum's website. Octagonal in shape, it depicts on one side what appears to be three lotus buds on water and on the other semi-circular figures surrounding a square design in the center, similar to the square described by Millies. But Robinson-Shaw fail to mention the most interesting feature of the coin: apparent Chinese characters above the semicircular patterns [15]. Later in 1986, when Michael Robinson publishes The Tin and Lead Coins of Pegu and Tenasserim, this miss gets corrected. The inscription was indeed Chinese characters, which are pronounced " $f u$ " and mean "good fortune" or "blessing." He contends they are in retrograde mode and were counter-stamped on the surface, meaning not part of the original coin [16]. One of the SARC coins (Lot 977) will also contain Chinese characters, but not as counterstamps, suggesting that Chinese minters were manufacturing these coins as well.

Acknowledging that much remains unknown about these coins, they end their chapter with a series of questions about the coins' origins, purposes, extent of use, time frames, metallurgy, and messaging. It would not be long before Robinson, without the assistance of Shaw, would attempt to answer some of them.

\subsection{Robinson's the Tin and Lead Coins of Pegu and Tenasserim}

Self-published and rather difficult to find, Michael Robinson's The Tin and Lead Coins of Pegu and Tenasserim [16] is the most thorough treatment we have of the large tin coins and weights of Tanintharyi. In all, he describes 80 large coins and eight hin: tha weights from private collections (including his own) and British, American and Malaysian museums or numismatic organizations, numbers that dwarf the totality of specimens from all other treatments. He also strives to follow up on the questions posed in [15] by providing metallurgical data on 23 coins and weights from either X-ray fluorescence or specific gravity tests and by proposing a possible evolution of the coins' designs and metallurgy from their first appearance in the seventeenth century. He also identifies the language found on the reverse of the better preserved lead weights (see Figure 14 for a comparable piece), the meaning of which has eluded all researchers to date [16]. Robinson describes it as "early mediaeval Burma-Mon script," but we should add that Phayre believed some of the letters on a similar weight were 
actually Persian [10]. Robinson provides no source for this language identification, but in his Introduction acknowledges the assistance of John Okell and Dr. Harold Shorto, who has translated Mon texts and compiled a Mon dictionary [16].

As it would be beyond the scope of this article to address all the points he makes in The Tin and Lead Coins, we will focus on one aspect that sheds light on the SARC collection: compelling information from the India Office Library in London establishing that these coins continued to be made in the nineteenth century before and just after the British annexation of Tanintharyi in 1825, thereby more firmly fixing the time frame during which these coins were manufactured. Documents from a file entitled "Correspondence in the office of the Commissioner of the Tenasserim division, 1825-6 to 1842-3" [17] not only indicate that some of the large tin coins were made prior to annexation at a "government mint" in Myeik, most probably operated by the local governor, but that the British, facing a shortage of small change upon annexation, had additional tin coins called pice made sometime in late 1825 and 1826 .

The story begins after the First Anglo-Burmese War with the appointment of A. D. Maingy and James Briggs as the Commissioner and Assistant Commissioner respectively of Dawei and Myeik. They arrived in Tanintharyi in August 1825 and between that time and September 1826 reported to Penang and not to the Government of India [16]. Maingy is an official with whom students of Tanintharyi society should be familiar, being renowned for his well-intentioned, but ultimately unsuccessful, attempt to incorporate Myanmar legal practices and traditions into the British court system [18-20]. We will discover that the legal arena was not the only area of administration where he attempted to adopt traditional systems.

We begin with an August 1825 report from Briggs, the Assistant Commissioner, regarding tin mining in the area. Located in the mountains, the mines were worked by only 30-40 men about six to eight weeks a year and their meagre output was brought to Myeik and smelted for the "Government Mint," meaning a mint established during Konbaung times. Although he cautioned his report was based on second-hand information and may not be dependable, this is the first indication we have of local governmental production of these coins [16]. But Maingy, writing on October 22, 1825, seems to weaken his assistant's case for the existence of a government mint. Referring to the meagre output of tin reportedly abundant in the hills east of both Dawei and Myeik, he continues,

No encouragement was given to its collection under the late Government and the people employed in it were subject to so many exactions that little more than 600 piculs [40 tons] were procured, and the whole converted into pice [16].

In other words, local tin may have been made into pice coins, but not by a discouraging and over-taxing government.

Yet another report by Maingy, dated October 12, 1825, appears to verify the existence of a former government mint and announces his intention to have similar coins minted to solve an evident shortage of small change. After noting that
Siamese tical coins, due to their lower and unreliable silver content, had been rejected in Tanintharyi and supplanted by Madras rupees, he goes on to state that Tanintharyi "ki-bia," or "large tin pice," were also in circulation but were scarce. These tin pice were worth about 36 to the Madras rupee and 40 to 44 to the sicca, or Bengal, rupee. He continues,

It is my intention to take the coinage of these pice entirely into my own hands and I shall send down from Tavoy a quantity sufficient to establish their true value, viz 50 for Sicca Rupee.... I will also allow every person to bring tin to be coined who may wish to do so on paying 10 per cent. The coinage of these tin pice was sometimes farmed. Tin was allowed to be exported in bulk from Mergui, but every person was obliged to bring what they had collected to the Government Mint in the first instance or to the farmer, and in both cases 10 per cent was taken besides any other charge which might arbitrarily be made [16].

This statement establishes that production of these coins was also "farmed out" to independents, which given the variety of this coinage appears quite likely. In a letter from Dawei dated October 1825, Maingy reports that the tin pice were more common there, 40 being equivalent to the rupee. He continues, "In the course of a few days I shall have coined a supply of them for both Mergui and this place and shall issue them as I have before stated at the rate of 50 for one rupee" [16].

Completely absent from other treatments, these reports are essential data for understanding the historical context of these coins. The British, upon annexing Tanintharyi and encountering a shortage of small change, had large tin coins made in Dawei, and possibly Myeik, by private parties or former government officials who had the skill and set their value versus the rupee. Robinson speculates that the bettermade tou: coins with the circular nagaran maha thu. khan inscription and an average weight of $32 \mathrm{~g}$ were the type most probably made under British direction (see Figures 3 and 4 for representative coins). He believes the average weight matches Maingy's standard of 50 to the rupee and their lack of wear indicates little time in circulation, which one would expect if they were the last to be made [16]. The final record concerning these large tin pice appears to be a letter dated February 26, 1826, from Maingy to Briggs regarding their value against the sicca and Madras rupees [17].

\subsection{The Research of Elizabeth Moore}

After Robinson [16], the only sources we encounter are two articles by Elizabeth Moore, an archaeologist at the School of Oriental and African Studies, regarding historical sites in the Tanintharyi region [21-22]. She initially posits the earliest appearance of these coins in the fifteenth century, shortly after the founding of the city of Weidi in $1390 \mathrm{CE}$, located on an estuary of the Dawei River south of Dawei town. Moore:

The most abundant artefacts of this era are large tin and lead coins, a form of trade exchange unique to Dawei. The manufacture of these lasted a number of centuries, highlighting widening international trade and including the 16th century CE Portuguese acquisition of Malacca [21]. Citing U Pe Nyan, a Myanmar source, she contends that 
most of these coins have been found in the region between Dawei and Myeik, with the greatest concentration in the area of Weidi. She continues, "Only a few of the lead and tin coins contain dates in inscriptions around the rim but all are generally dated to the 15-18th century CE" [21], an estimate later modified to the seventeenth to nineteenth century. Further evidence siting these coins in the Dawei area was the melting of these coins for bullets by insurgents occupying the Weidi site in the 1960's [22].

Of all the Tanintharyi coins examined so far, only one contains a date, pictured in her article, but the date is not specified and the photograph is too small for a confident translation [21]. We will be able to translate this coin when similar specimens appear in the SARC auctions (see Figure 9 below). She continues,

Recently found tin coins from the river near Sin Seik have a rooster-like bird on one side and the name "Dawei" on the reverse. The bird denotes the founding date of Dawei town, $1116 \mathrm{ME}$ by the mnemonic 'oh-aw-aw-the' (1-1-1-6) [21].

See Figures 16 and 17 for a coin of this type. Her source for this is U Than Swe, a local collector and historian, but no further explanation of the mnemonic device is provided. In an email exchange, Moore and a colleague advised the mnemonic for the founding date of Dawei appears to utilize the letters corresponding to the date's numbers in the Burmese astrological system. Those letters can be recalled through the bird's name ("Oh-aw"), which is probably the ou' o: [12] bird, or Asian koel found in India, China and Southeast Asia [23]. It is represented in this coin, they pointed out, through the shape of the bird's tail, which of the eleven SARC coins of this type Figure 6 is the best representation. Moore advised, however, that the matter is not entirely clear [27]. What is clearer is the identification of $1116 \mathrm{ME}(1754 \mathrm{CE})$ as the founding date of Dawei in its present location. Although the term "Dawei" had been used to label the region and its people before that time, the present town of that name is apparently only 265 years old. A king named Min-ne-hla founded it in $1116 \mathrm{ME}$, and though he originally called it Thayawaddy, it came to be known over time as Dawei [24].

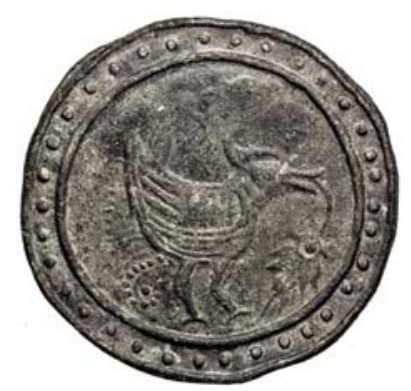

Figure 6. The obverse of a coin containing the 1-1-1-6 mnemonic device.

A matter of additional relevance to Tanintharyi coinage is Moore and Soe Thainkha's research into the history of Mokti, a walled city approximately 10 kilometers south of Dawei town that prospered from the eleventh to the fifteenth century. Upon its renaming in 1417 CE by King Min Taya, a palace, moat and walls were constructed and the town was named "Motta Thuka Nagara", translated as "pleasant place away from danger." Here we see an earlier usage of the thu. kha. nagaran expression, although with a slightly different interpretation, indicating it was traditional in Tanintharyi and could have been applied to any number of settlements in the region [22].

\subsection{Preliminary Conclusions}

Of the above treatments, only Robinson [16] and Moore [21] and [22] address the broader economic, political or cultural contexts surrounding Tanintharyi's coinage. Phayre primarily addressed the religious dimensions of the coins, while Temple devoted considerable space evaluating the monetary systems of pre-modern Island Southeast Asia and how they were adapted to the Dutch and British monetary systems. Yet he made little effort to similarly explain Tanintharyi coinage, of which he had a poor understanding. Nonetheless, we can now draw some preliminary conclusions.

Regarding the historical period in which they circulated, the earliest report places their appearance in the midseventeenth century, while others have their manufacturing and use continuing into the nineteenth century. Yet this dating comes entirely from European accounts, with the coins themselves remaining largely silent on the issue. Moore contends that a handful do contain dates, but only one type seems to have one, which will be translated below (see Figure 9). The date on Moore's 1-1-1-6 coin (1754 CE) appears to reference only the founding date of Dawei, not necessarily the year when the coin was made. We will examine another coin below that may also have a date, or at least commemorate an historical event like the 1-1-1-6 coin.

Whether these coins enabled "widening international trade" in the Tanintharyi region in the seventeenth and eighteenth centuries, brought on in part by the Portuguese seizure of Malacca [21], or were simply the result of greater trade activity in the region is more difficult to ascertain. In this respect, we should note that coins of "base metals," a numismatic term for tin, lead, copper or iron, were not normally employed in higher value maritime trade during the subject period. Although possibly used in commerce between Tanintharyi ports, the weight and size of these coins would render them relatively impractical for higher value transactions that by the time of the seventeenth century were financed primarily by an influx of New World and Japanese silver $[26,28]$. Yet the increase in trade through Tanintharyi's ports during this period, enhanced from the avoidance by Indian and Muslim merchants of both lower Myanmar (temporarily under the control of Filipe de Brito) and Malacca, and the establishment of Myeik as a significant Siamese entrepot [25-26, 29], would likely strengthen the need for small change to facilitate greater activity in local marketplaces. Indeed, by the seventeenth century the Portuguese had minted three denominations of tin coins in Malacca, a practice inspired it seems by the earlier tin coinage of the Malacca and Palembang sultanates [5, 30]. Thus, the weight of the evidence points to these coins supporting enhanced economic activity within Tanintharyi, 
the predominant use of these coins portrayed in European accounts and the use envisioned by British officials after annexation.

Robinson [16] goes further than the other treatments in answering the question of whether these coins were official issues of local governors or privately issued. British reports not only have private parties manufacturing these pice, but firmly establish the existence of a government mint in Myeik during Konbaung times. However, we should note that not a single king or regional governor is mentioned on the coins that have been read and reviewed so far (and the SARC coins will not contradict this), nor are there any allusions to royal titles, such as "lord of the white (or red) elephant" or "lord of the golden palace," as seen in Rakhine coinage [15]. Admittedly, the Dawei coin first revealed in Moore's research could have been manufactured officially, but British reports contain no evidence of a Konbaung era mint in Dawei.

To generate broad use and acceptance of these official and privately-made coins, they would need to reflect local culture and traditions, as demonstrated by the summary below of the 114 coins reviewed in the existing sources:

1) $44 \%$ contain maha thu. khan nagaran, or variations;

2) $37 \%$ depict a tou:

3) $29 \%$ depict sea dragons;

4) $19 \%$ depict a hin: tha or cock;

5) $7 \%$ depict geometric designs or semi-circles surrounding a cash coin square; and

6) $5 \%$ depict various animals not mentioned above (the break down exceeds $100 \%$ as some coins contain more than one element).

Considering these major categories, the SARC coins demonstrate roughly comparable percentages, but overall possess less variety than the above.

\section{The Stephen Album Coins}

With the above background in mind, the 125 coins of the major collection auctioned on SARC's website since January 2019 can be summarized as follows:

1) $52 \%$ contain maha thu. khan nagaran, or variations, mostly in retrograde form;

2) $50 \%$ depict sea dragons;

3) $34 \%$ depict a hin: tha or cock;

4) $16 \%$ depict a tou;

5) $13 \%$ are weights usually depicting a hin: tha;

6) $12 \%$ contain indecipherable Burmese or Mon writing; and

7) $9 \%$ display the word "Dawei" in an older spelling, as first shown in Moore [21] (the break down exceeds $100 \%$ as some coins contain more than one element).

We will now focus on seven specimens that are previously unreported or may provide insights into Tanintharyi society during the subject time period. All data or quotations from the SARC cataloguer can be found at the Steven Album website and all photos are courtesy of Stephen Album Rare Coins [31].

Lot 977, Auction 33, January 2019: this is an octagonal tin coin of $30.39 \mathrm{~g}$ (1.07 ounces), $57 \mathrm{~mm}$ in diameter (2.24 inches), similar to that depicted as Robinson no. 9, Plate 7.5 [16]. The obverse has a hin: tha facing right above which are two Chinese characters that do not appear to be counterstamped and are translated by the SARC cataloguer as min an, "the people of peace." Per the SARC cataloguer, the reverse displays "stylized Burmese characters" that Phayre called chaitya, or stupa-like semi-circles [10], but on these coins have the appearance of wave or cloud patterns. The square device in the center, once characterized by Phayre as a pagoda relic chamber [10], is now believed to be a representation of a Chinese cash coin the purpose of which was to designate the item as money (Figures 7 and 8).

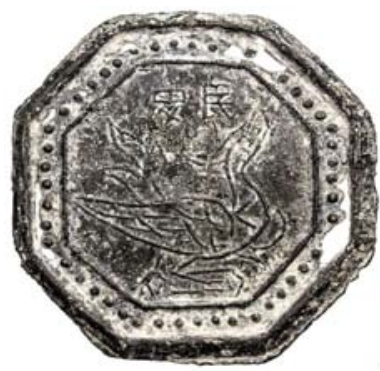

Figure 7. The obverse of Lot 977 with Chinese characters.

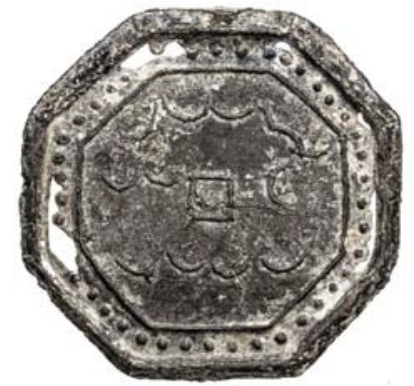

Figure 8. The reverse of Lot 977 with a cash coin square.

The octagonal shape probably dates this coin to the $17^{\text {th }}$ century, per Tavernier's observations, which when combined with the Chinese characters provides evidence of Chinese communities in the Tanintharyi region as early as the 1600's, although evidence for their presence in Myeik during the 1500's has been uncovered [25].

Lot 1002, Auction 33: this is a larger tin coin of $72.03 \mathrm{~g}$ (2.54 ounces), $69 \mathrm{~mm}$ in diameter (2.72 inches), similar to Robinson no. 18, plate 10.1 [16] and also pictured in Moore [21]. It depicts a hin: tha or cock facing right, with a Burmese legend encircling the bird that has been only partially translated by earlier researchers. The reverse depicts a sea dragon and is otherwise unremarkable (Figures 9 and 2).

To fully translate the inscription, we should start with the Burmese letter adjacent to the cock's right claw (viewer's right) where we find nagaran maha thu. khan going clockwise in non-retrograde form. The kha. gwei:, or initial consonant of khan, is similar to an older form described in [12] as "Lithic 16-18 AD." Moore and the SARC cataloguer correctly translate this as "City of great happiness," but the remainder of the inscription has not been translated and is of 
great importance in correctly dating these coins (a similar specimen in Robinson [16] is so deteriorated the rest of the inscription cannot be read). To the right of khan, and starting at the 12 o'clock position, we find the word and numbers dhagaji' 971, which means Myanmar Era 971, or 1609 CE [12]. This is the only Tanintharyi coin reviewed herein with a certain date (Lot 1011 with a possible date will be addressed below), and confirms the issuance of these coins as early as the beginning of the seventeenth century. Although this translation may be a first outside Myanmar, Myanmar collectors would have probably read the entire inscription when this type was originally found as dhagaji' is found on several nineteenth century Myanmar coins. We will call this the "Dhagaji' 971 Coin."

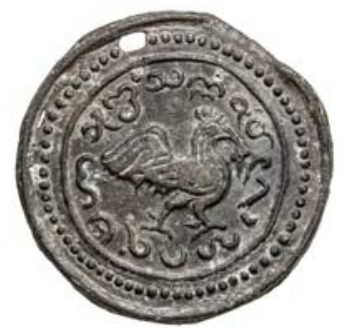

Figure 9. The obverse of the Dhagaji'971 Coin.

Lot 1011, Auction 33: this is a uniface cast tin-lead weight of $125.98 \mathrm{~g}$ (4.45 ounces), $60 \mathrm{~mm}$ in diameter (2.36 inches), depicting the crude outline of a bird, probably a hin: tha, surrounded by a stippled field. The SARC cataloguer characterized the four figures at the six o'clock position as parts of the bird's body, but I respectfully submit a different interpretation of these figures for consideration. This four figure inscription is completely separate from the bird's feathers, feet, tail and the five vertical strokes on both sides of the body that probably denote the ground or grass. The inscription appears to consist of three Arabic numeral " 1 's" and a Burmese eight (which has the general appearance of an upside-down "u") or the date 1118 Myanmar Era, $1756 \mathrm{CE}$ (Figures 10 and 11).

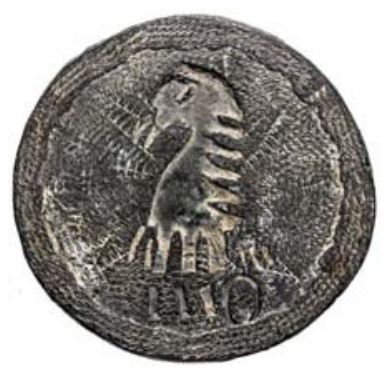

Figure 10. The 1118 Coin.

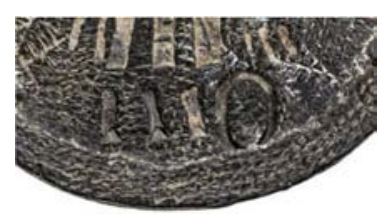

Figure 11. A close-up of the date of the 1118 Coin.
Whether this date, if valid, represents the year coin was made or commemorates an historical event is not presently known. The research for this article has not identified an historical event in Tanintharyi in 1756 CE. The utilization of three Arabic "1's" would, however, indicate a European influence, a definite possibility since Portuguese, Dutch, French and English traders were present in Tanintharyi during this period $[20,18,8,28]$. The author considers this date possible, but not certain, and proposes it solely for consideration. We should note that the utilization of retrograde writing and older and dialectal spellings makes translation of these coins more of an art than a science and subject to reasonable differences of opinion. This specimen, probably unique, will be called the " 1118 Coin."

Lot 1852, Auction 35, September 2019: this is a large octagonal tin coin of $78.61 \mathrm{~g}$ (2.77 ounces), $56 \mathrm{~mm}$ in diameter (2.20 inches), depicting an elephant on ground facing right. Above the elephant is an inscription too worn to be legible. The reverse contains semi-circular patterns resembling waves or clouds, as in Lot 977, surrounding a small square in the center representing a Chinese cash coin (Figures 12 and 13).

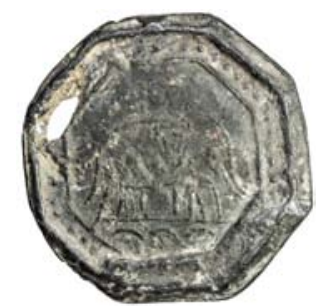

Figure 12. The obverse of Lot 1852 showing the elephant.

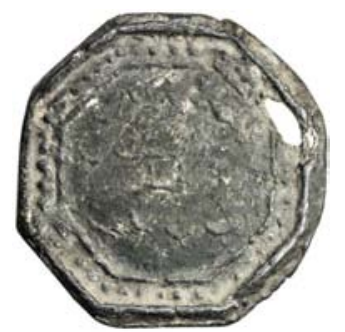

Figure 13. The reverse of Lot 1852.

Although considerable wear, or poor casting, takes away from the overall appearance, the coin is unpublished and only one other elephant type has ever appeared for sale, in SARC's Auction 37 of June 2020. As noted by the SARC cataloguer, all previously published octagonal types depict either lotus buds, a hin: tha or a sea dragon, and of the two elephant coins now seen, this is the superior specimen.

Lot 1854, Auction 35: this is a lead weight of $525 \mathrm{~g}$ (18.53 ounces, 1.16 pounds), $72 \mathrm{~mm}$ in diameter (2.83 inches), similar to Robinson Plate 5.3 and 6.2 [16] and Phayre coin \#2, Plate III [10], depicting on the obverse a hin: tha in fine style with a long tail and beak. On the reverse, per the SARC cataloguer, is an inscription in seven lines that has never been translated (Figures 14 and 15). 


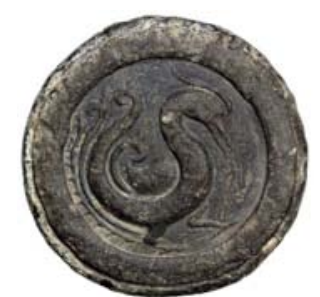

Figure 14. The obverse of Lot 1854, the largest lead weight found to date.

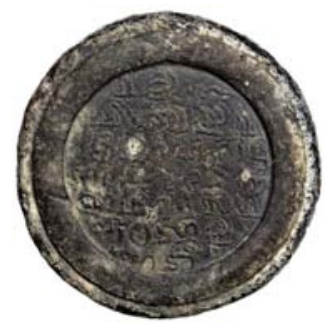

Figure 15. The inscription side of Lot 1854.

As previously mentioned, Robinson called this writing medieval Mon-Burmese, while Phayre believed some of the letters were Persian. According to the SARC cataloguer, this is the heaviest Tanintharyi weight ever found and one of the finest known of this type. Prior to its appearance the heaviest specimen was Robinson Plate 5.4 at $456.85 \mathrm{~g}$ [16].

Lot 1866, Auction 35: this is a tin coin of $52.70 \mathrm{~g}(1.86$ ounces), $69 \mathrm{~mm}$ in diameter (2.72 inches), depicting on the obverse a hin: tha or rooster-like bird facing right with an elongated tail and holding a nine-leaf branch in its beak. The reverse contains the Burmese word tawe:, an older spelling for the city of Dawei, and demonstrates a superb casting of the type first published in Moore [21] (Figures 16 and 17).

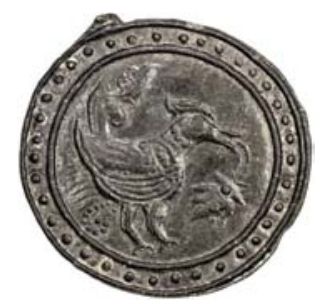

Figure 16. The obverse of the Dawei Coin.

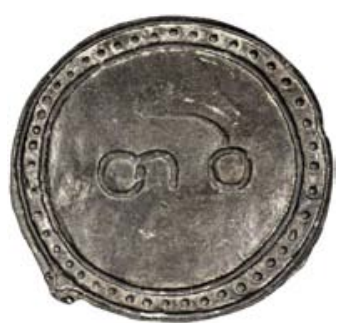

Figure 17. The reverse of the Dawei Coin.

The SARC cataloguer describes this specimen as the finest of the eleven Dawei specimens they have sold since January 2019. We will call this the "Dawei Coin."

Lot 1633, Auction 37, June 2020: this is a tin coin of 36.40 $\mathrm{g}$ (1.28 ounces), $63 \mathrm{~mm}$ in diameter (2.48 inches), which according to the SARC cataloguer was a weakly cast sea dragon type that had the remaining features removed for purposes of overwriting a cabbalistic in:. The photo shows the most interesting side, featuring a five-by-five square containing various Burmese letters, syllables and words (Figure 18). Among the discernible words are wa, "cotton" or "period of monsoon retreat for Buddhist monks," thei, "to die," kho:, "small basket in which offerings are presented to evil spirits," and maha, "great" [12]. The predominant significance appears to be religious, but dialectal variations may result in different meanings.

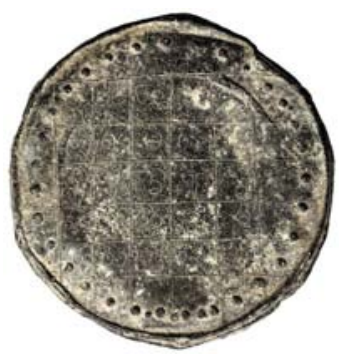

Figure 18. A coin with an overwritten cabbalistic in:

The SARC cataloguer describes it as a "most interesting piece" as it demonstrates that these coins, once overwritten, might also serve as amulets bestowing upon the owner either magical powers or protection from malevolent forces.

In closing, of the approximately 240 coins described in the existing literature and the SARC auctions, we find no references to royal titles, kings or regional governors, despite evidence of a government mint in Myeik during Konbaung times. In fact, the only urban center mentioned is Dawei, not Myeik. Instead, the most common feature is the inscription "city of great happiness," an expression more religious than political that appears to have been applied to many locales in Tanintharyi as early as the fifteenth century. Thus, it seems safe to conclude these coins speak entirely of cultural traditions within Tanintharyi.

In recent years, we have seen in Myanmar studies the utilization of numismatic evidence, in combination with other evidence, to "recontextualize" Rakhine history, an endeavor driven no doubt by the on-going controversy over the proper place of Muslims in Rakhine history and society [32]. In contrast, the author does not believe the evidence derived from this recent and impressive appearance of Tanintharyi coinage can be used in the same fashion to re-contextualize Tanintharyi history. These coins lack the political references and allusions, such as "lord of the elephant," that would be necessary to better interpret or contextualize other historical evidence. The only subtle messaging we do find is the mnemonic device of the Dawei Coin, hardly a feature that points to political under currents or cultural processes not readily visible through existing sources.

\section{Conclusion}

Having examined the existing literature and a sampling of the SARC coins, we can conclude the following:

1) The available evidence dates the manufacture and use of these coins from the early seventeenth century to the 
first 25 years at least of the nineteenth century. It is possible some were made earlier, as were tin coins in the Malay States and Palembang, but European reports and the coins themselves do not support this.

2) What is known about maritime commerce in Tanintharyi during this period points to a role for these coins in local economies and marketplaces and not in higher value trade between entrepots.

3) British reports and the considerable variety of this coinage indicate a practice of both official and private issuance, with local governors and private parties utilizing cultural icons and traditions to generate acceptance of this medium of exchange.

This numismatic evidence in the main supports the prevailing historical narrative that the Tanintharyi region, between the Taungoo Dynasty's loss of Tanintharyi to Ayuthia in 1590's and the assertion of Konbaung control in the 1760's, experienced varying degrees of independence from, or domination by, the kingdoms of Myanmar and Siam, depending on time and place, which when combined with Chinese, European and maritime interactions resulted in a relatively unique cultural identity. The sea dragon, Chinese character and "cash square" coins, and speculatively the 1118 Coin, reflect Tanintharyi's foreign influences and maritime culture, while the Dhagaji' 971 and Dawei Coins (and again speculatively the 1118 Coin) place this coinage in the Tanintharyi region during the subject time frame.

Oftentimes researchers focus so much on what is present that they do not notice what is absent and fail to ask Sherlock Holmes' famous question, "why didn't the dog bark?" Conspicuous for its absence, not a single element of Thai script has been found on these coins to date. This is not to question the historical narrative of varying degrees of Siamese suzerainty over portions of Tanintharyi during this period, particularly the port of Myeik. Yet what we find in these coins is the overwhelming utilization of Burmese inscriptions, demonstrating the persistence of Tanintharyi's unique culture in spite of Siamese, European and Chinese influences upon the region.

\section{Acknowledgements}

I would like to thank Michael W. Barry, Chief Operations Officer of Stephen Album Rare Coins, for permission to use their photography and quote their cataloguer. Special thanks goes to Dr. Elizabeth Moore and her colleagues at the School of Oriental and African Studies for their insights into the Dawei Coin and prompt return of my emails. Thanks also goes to Steven M. Nagata, Esq. for his assistance in finding Michael Robinson's The Tin and Lead Coins of Pegu and Tenasserim. Without their help, this article would not be possible.

\section{References}

[1] Stacks Bowers.

https://archive.stacksbowers.com/?q=04e3beda-3d46-43e9804b-0858ef70dfcb, accessed June 18, 2020.
[2] Heritage Auctions. 2020. https://www.ha.com/c/searchresults.zx? $\mathrm{No}=120 \& \mathrm{Nty}=1 \& \mathrm{Ntk}=\mathrm{SI}$-TitlesDesc\&N=790+231\&Ntt=burma' accessed June 18, 2020.

[3] Stephen Album Rare Coins email with the author, July 10, 2020.

[4] Nightingale, Benjamin, W. B. Dickinson and Henry Christmas. "Tin-money of the trading ports of the burman empire," The Numismatic Chronicle and Journal of the Numismatic Society, vol. 7, pp. 27-34, 1844-1845.

[5] Temple, R. C. "The obsolete tin currency and money of the federated Malay states," The Indian Antiquary, vol. 42, pp. 85-132, 153-58, 181-85, 209-16, 237-39, 253-54, 273-76, Plate III, 1913.

[6] Low, James. "History of Tennasserim," The Journal of the Royal Asiatic Society of Great Britain and Ireland, vol. 3, no. 2, pp. 287-336, 1836.

[7] Sangermano, Father. A description of the Burmese empire. London: Susil Gupta, (1833) 1966, p. 214.

[8] Harvey, G. E. History of Burma: from the earliest times to 10 March 1824, the beginning of the English conquest. London: Frank Cass and Company Limited, 1925, pp. v, 122, 132-33, 202-03.

[9] Temple, R. C. The thirty-seven nats: a phase of spiritworship prevailing in Burma. London: Paul Strachan Kiscadale Publications, [1906] 1991, p. II.

[10] Phayre, Arthur P. "Coins of Arakan, of Pegu, and of Burma," The International Numismata Orientalia, vol. III, no. 1, pp. 1-44, Plates III and V, 1882.

[11] Yule, Henry. A narrative of the mission to the court of Ava in 1855: together with the journal of Arthur Phayre envoy to the court of Ava. London: Oxford University Press, [1856] 1968, pp. vii-ix.

[12] Myanmar Language Commission. Myanmar-English dictionary. Kensington: Dunwoody Press, 1996, pp. xv, 8, $58,220,336,369,472,496-97,499,507,610,623$.

[13] Mitchiner, Michael. Oriental coins and their values: nonIslamic states \& western colonies AD 600-1979. London: Hawkins Publications, 1979, pp. 367-68.

[14] Ponder, Richard D. "Early fakes," The Numismatist, vol. 133, no. 9, pp. 49-50, 2020.

[15] Robinson, M. and L. A. Shaw. The coins and banknotes of Burma. Manchester: M. Robinson and L. A. Shaw. 1980, pp. vii, 37-42, 54-62, 155.

[16] Robinson, M. The lead and tin coins of Pegu and Tenasserim. Cheshire, England: M. Robinson, 1986, pp. iv, $38-40,45,50,55-57,68$.

[17] Office of the Superintendent. Correspondence for the years 1824-26 to $1842-48$, in the office of the commissioner, Tenasserim division. Rangoon: Government Printing, 1929, pp. 7, 44.

[18] Aung-Thwin, Michael and Maitrii Aung-Thwin. A history of Myanmar since ancient times: traditions and transformations. London: Reaktion Books Ltd., 2012, pp. $145-46,154,182-83$.

[19] Taylor, Robert H. The state in Myanmar. Honolulu: University of Hawaii Press, 2009, pp. 103-04. 
[20] Maung Htin Aung. A history of Burma. New York: Columbia University Press, 1967, pp. 145-46, 219.

[21] Moore, Elizabeth. "Dawei Buddhist culture: a hybrid borderland," Myanmar Historical Research Journal, vol. 21, pp. 1-62, 2011

[22] Moore, Elizabeth and Soe Thainkha. "The ancient city of Mokti in the tenth to thirteenth century CE Bagan period," Sojourn: Journal of Social Issues in Southeast Asia, vol. 34, no. (1), pp. 149-184, 2019.

[23] “Asian Koel," https://en.wikipedia.org/wiki/Asian_koel, accessed December 22, 2020.

[24] Ma Aye Sandi. The Social Organization of the Dawei National, Dawei Township, Taninthayi Division, Union of Myanmar. Yangon, MA dissertation, Department of Anthropology, University of Yangon, 1999, p. 7.

[25] Mills, J. A. "The swinging pendulum: centrality to marginality - a study of southern Tenasserim in the history of Southeast Asia," Journal of the Siam Society, vol. 85, nos. 1 and 2, pp. 35-58, 1997.

[26] Lieberman, Victor B. Burmese administrative cycles: anarchy and conquest, c. 1580-1760. Princeton: Princeton University Press, 1984, pp. 27-28, 121-24, 156-59.
[27] Moore, Elizabeth and colleague emails with the author, July 12 and 17 and December 18, 2020.

[28] Subrahmanyam, Sanjay. The Portuguese empire in Asia, 1500-1700: a political and economic history. London: Longman Group UK Limited, 1993, pp. 71-72, 103-05, 169.

[29] Charney, Michael W. "Crisis and reformation in a maritime kingdom of Southeast Asia: forces of instability and political disintegration in western Burma (Arakan), 16031701," Journal of the Economic and Social History of the Orient, vol. 41, no. 2, pp. 185-219, 1998.

[30] Robinson, Frank S. "Palembang coins," www.fsrcoin.com/palembang, no date.

[31] Stephen Album Rare Coins https://db.stevealbum.com/php/auctions.php?site $=0 \&$ lang= $1 \&$ cust $=0$, Auctions 31 to 37 inclusive, accessed June 2020.

[32] D'Hubert, Thibaut. "The lord of the elephant: interpreting the Islamicate, numismatic, and literary material from the Mrauk U period of Arakan (ca. 1430-1784)," The Journal of Burma Studies, vol. 19, no. 2, pp. 341-369, 2015. 